\title{
Monetary-Fiscal Wage Interactions in a Multi-Country Currency Union
}

\author{
Marcelo Sánchez \\ European Central Bank, Frankfurt, Germany
}

\begin{abstract}
This paper studies a multi-country currency union of small open economies. Demand-side disturbances hamper monetary union stabilisation unless participating countries' business cycles are perfectly synchronised. In the face of country-specific supply shocks, a currency union of small open economies underperforms monetary autonomy. Higher preference for price stability also deteriorates monetary union stabilisation performance. Monetary-fiscal interaction leads to a free rider problem, with supply shocks eliciting higher interest rate variability. Wage bargaining attempting at stabilising real wages and output mitigates the free rider problem. Decentralised wage bargaining and a lower wage sensitivity of output favour a currency union over monetary autonomy.
\end{abstract}

JEL Classifications: E52, E58, E63, F33, F42

Key words: Monetary Union, Stabilisation, Welfare, Small Open Economies, Fiscal Policy, Wage Setting

\footnotetext{
* Corresponding Author: Marcelo Sánchez; European Central Bank, Kaiserstrasse 29., D-60311 Frankfurt am Main, Germany; Tel: +49 6913446531, Fax: +49 6913446531, E-mail : marcelo.sanchez@ecb.int. 


\section{Introduction}

A large number of studies have been devoted to the experience and outlook for monetary integration around the globe over the last fifty years. We extend the existing literature on currency unions in two ways. First, here the single monetary policy interacts with both national fiscal policies and wage-setting trade unions. The analysis delves into the fiscal free rider problem (see Chari and Kehoe 2008; Sánchez 2008b; Uhlig 2003) alongside the role of labour market institutions. ' Our study attempts to provide insights as to how wage setting considerations affect the free rider problem and monetary stabilisation performance. Second, we set up a multi-country framework, drawing on recent work on small open economies, as spawned by Ball $(1999,2002)$ and Svensson $(2000)$. We propose a setup with a broad set of shocks, which are allowed to be country-specific. We evaluate monetary stabilisation properties of a currency union by means of welfare simulations, including sensitivity to structural factors such as country size, trade openness, preference for price stability, and cross-country distribution of shocks. Finally, we pursue a game theoretic approach. The agents making decisions simultaneously (be it fiscal authorities or trade unions) are assumed not to cooperate in their choices, which leads to coordination failure.

The structure of the rest of the paper is as follows. In Section II the model is laid out. The study of a currency union is preceded by that of optimal autonomous monetary policy. Section III presents quantitative results on stabilisation performance relative to monetary autonomy as well as the corresponding sensitivity analysis. Section IV concludes.

\section{A Simple Model of Monetary Union Stabilisation}

In order to investigate monetary stabilisation policy in a currency union, let us consider a simple small open economy model. Four equations describe the behaviour of the private sector in each country $i$ with $i=1,2, \ldots, n$.

$$
\begin{aligned}
& y_{i}=\alpha\left(\pi_{i}-\pi_{i}^{e}\right)-\lambda\left(\pi_{i}^{w}-\pi_{i}^{e}\right)+\varepsilon_{i} \\
& y_{i}=-\beta r_{i}-\delta e_{i}+g_{i}+\varsigma_{i}
\end{aligned}
$$

\footnotetext{
${ }^{1}$ The fiscal free rider problem arises in a context where national governments have incentives to respond to macroeconomic developments, creating aggregate demand pressures that induce higher interest rates. For multi-country models of pure monetary-fiscal interaction, see Dixit and Lambertini (2001, 2003) and Galí and Monacelli (2008). The latter's optimising approach is not able to assess the implications of country size due to its assumption that each country is infinitesimal. For an applied multi-country analysis, see Sánchez (2006).
} 


$$
\begin{aligned}
& r_{i}=\theta e_{i}+\varepsilon_{i}^{f} \\
& r_{i}=R_{i}-\pi_{i,+1}^{e}
\end{aligned}
$$

where all variables but inflation are deviations from steady state values. Output $\left(y_{i}\right)$ and real exchange rate $\left(e_{i}\right)$ are in logs. All parameters are positive. All shocks are with the zero mean, constant variance. They are also assumed to be uncorrelated with each other for economy $i$, but correlated across countries.

Equation (1) is a simple aggregate supply curve in which output responds positively to surprises from the last period's expectations of the inflation level $\left(\pi_{i}-\pi_{i}^{e}\right)$. We add a role for real wage pressure $\left(\pi_{i}^{w}-\pi_{i}^{e}\right)$, but we do not include an exchange rate pass-through term as the latter can be seen as simply affecting the inflation target in an additive fashion (Ball 2002; Sánchez 2008a). ${ }^{2}$ Equation (2) states that aggregate demand decreases in short-term real interest rate $\left(r_{i}\right)$ and real exchange rate $\left(e_{i}\right)$. Increases in $e_{i}$ denote real appreciation. We also include the public deficit term $g_{i}$. Equation (3) postulates a positive link between interest rates and exchange rates that can be interpreted to mean that higher interest rates encourage capital inflows, which lead to an appreciation. Other determinants of exchange rates, such as investor confidence and expectations, are captured by the error $\varepsilon_{i}^{f}$. Finally, Equation (4) is the Fisher equation defining the real interest rate as a difference between nominal interest rate and the current period's expectation of future inflation or $\pi_{i,+}^{e}$. Positive values for $\varepsilon_{i}$ and $\varsigma_{i}$ represent favourable supply and real demand shocks, respectively, while a positive value for $\varepsilon_{i}^{f}$ is interpreted to reflect an adverse risk premium shock.

The model assumes that there is only one good, which is internationally traded. We leave for further work the analysis to the case where one distinguishes between tradables and nontradables (Sánchez 2007a, 2008c). In this case, the real exchange rate can be interpreted as the relative price between the two types of goods, and inflationary pressures can differ across the two sectors. ${ }^{3}$ Sectoral productivity differentials are among the structural factors that may give rise to persistent inflation differentials between monetary union members. Temporary inflation differentials could be due to idiosyncratic shocks of the type that are accounted for in the present model. The disturbances included in our model could arise from internal forces or from foreign demand factors weighing on net trade and capital flows. Rather than differentiating between internal and external shocks, we simply allow shocks to respond to unexpected developments that occur domestically or abroad.

\footnotetext{
${ }^{2}$ Supply disturbances can be interpreted as productivity shocks. These shocks average zero, so they cannot capture technological progress over time.

${ }^{3}$ Depending on the type of developing economy in question, it would be important to specify the variety of products that are traded internationally (e.g., commodities or industrial goods), the degree of openness regarding portfolio flows, the approach adopted by the authorities to attract foreign technologies, etc.
} 
Each national fiscal authority is assumed to minimise

$$
L_{g i}=\frac{1}{2}\left[y_{i}^{2}+\gamma\left(g_{i}-\varepsilon_{g i}\right)^{2}\right]
$$

where $r$ is the weight put on a balanced budget relative to stable economic activity. Term $\varepsilon_{g i}$ reflects changes in the deficit that may arise randomly, as resulting from spending needs or available revenues differing from their projected values.

As in Onorante (2006), trade unions are concerned about economic instability and real wage flexibility. Each trade union $j$ (with $j=1,2, \ldots, m$ ) minimises

$$
L_{w i}=\frac{1}{2}\left[y_{i}^{2}+\kappa\left(\pi_{i j}^{w}-\tilde{\pi}_{i}\right)^{2}\right]
$$

where $\kappa$ is the weight on real wage flexibility concerns relative to output stability. The use of a quadratic formulation for union preferences is standard in the literature concerned with the macroeconomic impact of union wage setting. In most cases, the loss function concerns unemployment rather than output, although these two variables are closely connected (Herrendorf and Lockwood 1997; Hutchison and Walsh 1998; Bratsiotis and Martin 1999; Holden 2005; Calmfors and Johansson 2006). Oswald (1985) provides a microeconomic rationale. The quadratic specification means that unions dislike movements in both output and real wage around their target values. Equation (6) implicitly supposes that the target values of both output and real wage are consistent with expected labour market clearing. Although unions have a monopoly of power within their individual labour markets, they are assumed not to exploit it in such a way as to raise the real wage above its expected market-clearing value.

\section{A. Autonomous monetary policy}

Under monetary autonomy, the national central bank minimises the loss function

$$
L_{i}=\frac{1}{2}\left[y_{i}^{2}+\chi\left(\pi_{i}-\tilde{\pi}_{i}\right)^{2}\right]
$$

which penalises the deviations of both output and inflation from the target, the latter being defined as $\tilde{\pi}_{i}$ in the case of inflation. Parameter $\chi$ denotes the weight of inflation aversion of the central bank relative to the aim of achieving output stabilisation. The central bank has no incentive to surprise the private sector with inflation, and there is thus no inflation bias.

We assume that country $i$ 's public knows $\alpha, \beta, \delta, \theta, \chi, \gamma, \kappa$ and $\tilde{\pi}_{i}$. The game proceeds as follows. First, the public sets its inflation expectations $\left(\pi_{i,+}^{e}\right)$. Shocks $\varepsilon_{i}, \varsigma_{i}, \varepsilon_{i}^{f}$ and $\varepsilon_{g i}$ are then drawn. Next, each trade union $j$ sets $\pi^{w}$. After, the fiscal authority sets the deficit $g_{i}$. Finally, 
the autonomous monetary authority chooses the nominal interest rate $R_{i}{ }^{4}$ We solve the model backwards. Given inflation expectations, fiscal deficit levels and wage demands, the national central bank solves its optimisation problem, and one can then solve expected inflation. However, since the monetary policy rule is found to be linear in the shocks, computational burden is alleviated by imposing the result that expected inflation equals the targeted level (also assumed to be credible). Thus, in Equation (4), $r_{i}=R_{i}-\tilde{\pi}_{i}$. Using this alongside Equations (1) and (2), we obtain the monetary policy reaction function

$$
R_{i}=\frac{1}{d}\left[-A \varepsilon_{i}+g_{i}+\vartheta_{i}+\lambda A\left(\pi_{i}^{w}-\tilde{\pi}_{i}\right)\right]
$$

where $A \equiv \chi /\left(\alpha^{2}+\chi\right), d \equiv \beta+c, c \equiv \delta / \theta$ and $\vartheta_{i}=\varsigma_{i}+c \varepsilon_{i}^{f}+d \tilde{\pi}_{i}$. Composite expression $\vartheta_{i}$ captures the full set of exogenous factors operating through the demand side as opposed to $\varepsilon_{i}$ which works through the supply side.

The national fiscal authority chooses $g_{i}$ to minimise Equation (5) subject to interest rate rule Equation (8). The solution is simply given by $g_{i}=\varepsilon_{g i}$ as the fiscal authority recognises that its response to the disturbances other than $\varepsilon_{g i}$ would be fully offset by the monetary authority. Taking into consideration this and Equation (8), output can be expressed as

$$
y_{i}=A \varepsilon_{i}-\lambda A\left(\pi_{i}^{w}-\tilde{\pi}_{i}\right)
$$

Only supply-side influences affect output and inflation in equilibrium. The demand pressures generated by fiscal shock $\varepsilon_{g i}$ fail to affect output and inflation, being instead fully offset by higher interest rates as can be seen in Equation (8).

Trade union $J$ chooses its wage demand $\pi_{i J}^{w}$ to minimise Equation (6) subject to Equation (9). In so doing, it takes into account the role of $\pi_{i J}^{w}$ in overall wage growth, $\pi_{i}^{w}$, as given by

$$
\pi_{i}^{w}-\tilde{\pi}_{i}=\frac{\pi_{i J}^{w}-\tilde{\pi}_{I}}{m}+\frac{m-1}{m}\left(\bar{\pi}_{i J}^{w}-\tilde{\pi}_{i}\right)
$$

where $\bar{\pi}_{i J}^{w}$ is the weighted average of wage growth for unions other than $J$. Aggregating over individual trade union's choices can be found to yield

$$
\pi_{i}^{w}=\tilde{\pi}_{i}+\frac{\lambda A^{2}}{(\lambda A)^{2}+m \kappa} \varepsilon_{i}
$$

National wage inflation $\pi^{w}{ }_{i}$ deviates in equilibrium from target inflation by a term affected by supply shocks.

\footnotetext{
${ }^{4}$ Wage decisions are assumed to be taken first because wages tend to be set for many years and the contracting process is much more dispersed with a large number of trade unions in a given country (Onorante 2006). On the implications of informational frictions in this type of models, see Sánchez (2007b).
} 
In the light of the interactions among the three parties involved (the central bank, the fiscal authority, and the group of trade unions), the following expressions can be derived for the policy reaction function, output, and inflation:

$$
\begin{array}{r}
R_{i}=\frac{1}{d}\left[-\frac{m \kappa}{(\lambda A)^{2}+m \kappa} A \varepsilon_{i}+\varepsilon_{g i}+\vartheta_{i}\right] \\
y_{i}=\frac{m \kappa}{(\lambda A)^{2}+m \kappa} A \varepsilon_{i} \\
\pi_{i}=\tilde{\pi}_{i}-\left(\frac{1-A}{\alpha}\right) \frac{m \kappa}{(\lambda A)^{2}+m \kappa} \varepsilon_{i}
\end{array}
$$

The last two equations indicate how optimal monetary policy splits the cost of the supply shock across the output gap and inflation. The fraction $m \kappa /\left[(\lambda A)^{2}+m \kappa\right]$ is bound above at Equation (1), indicating that wage bargaining is a stabilising factor in the response of both $y_{i}$ and $\pi_{i}$ to supply shocks. This stabilising property, however, appears to fade away as wage bargaining becomes more decentralised (larger $m$ ). Finally, replacing Equations (13) and (14) into Equation (7) allows us to compute a value for the loss function $L_{i}$.

Parameter $\alpha$ plays an important role (be it directly or via $A$ ) in equilibrium output and inflation, and thereby in domestic loss functions. For welfare simulation purposes, we shall later work with its inverse $\alpha^{\prime} \equiv 1 / \alpha$, which we will refer to as the slope of the supply curve. Parameter $\alpha$ can be seen as being negatively related to the degree of openness of the economy. The reason is that, for a given real exchange rate depreciation associated with output expansion, the inflationary effect is larger the more open the economy is (Romer 1993). Therefore, the higher the degree of openness, the larger the rise in overall prices as the price increase in tradable goods exceeds that in non-tradables. A steeper supply curve entails monetary stabilisation costs since a supply shock makes the deviation of inflation from a target larger for a given change in the output gap.

\section{B. Monetary union stabilisation}

When every country $i$ (with $i=1,2, \ldots, n$ ) participates in a monetary union, the problem changes from the previous one by having the currency union's (as opposed to the national) central bank minimise

\footnotetext{
${ }^{5}$ For a review of the theoretical and empirical literature on the inverse link between size and openness, see Alesina et al. (2005). This relationship is far from simple, as documented in Alesina and Spolaore (2003). In addition to having supply-side effects, openness could also influence the demand side of the model. However, Erceg et al. (2009) conclude that openness only seems to matter for calibrations that impose an implausibly high trade price elasticity.
} 


$$
L_{u}=\frac{1}{2}\left[y_{u}^{2}+\chi_{i}\left(\pi_{u}-\tilde{\pi}_{u}\right)^{2}\right]
$$

Individual country loss function in Equation (7) is considered to represent society's preferences in any country $i$. The informational assumptions are also analogous to those made earlier in this section. With regard to timing, the game has the following sequence. First, the public sets its inflation expectations $\pi_{i+1}^{e}$ Afterwards, the disturbances $\varepsilon_{i}, \varsigma_{i}, \varepsilon_{i}^{f}$ and $\varepsilon_{g i}$, for country $i$, are drawn. Next, each trade union $j$ sets $\pi_{i j}^{w}$ in each country $i$. After which, the fiscal authority in each country $i$ sets the deficit $g_{i}$. Finally, the single monetary authority sets the nominal interest rate $R$.

To solve the model, we take averages over Equations (1)-(4) and use the outcome when minimising Equation (15). This leads to the following single monetary policy reaction function:

$$
R=\frac{1}{d}\left[-A \varepsilon_{u}+\vartheta_{u}+g_{u}+\lambda A\left(\pi_{u}^{w}-\tilde{\pi}_{u}\right)\right]
$$

which shows that $R$ is raised in the face of adverse supply shocks, favourable exogenous demand factors (involving both the private sector and the governments), and positive deviations of wage growth from expected inflation, unless these exogenous factors are purely asymmetric.

A given national fiscal authority solves its optimisation problem by choosing $g_{i}$ to minimise Equation (5) subject to the constraint given by Equation (16). This yields

$$
g_{I}=\frac{\gamma n^{2}}{\gamma n^{2}+(n-1)^{2}} v_{I}+\frac{n(n-1)}{\gamma n^{2}+\left(n^{-1}\right)^{2}} d \tilde{H}+\frac{n(n-1)^{2}}{\gamma n^{2}+\left(n^{-} 1\right)^{2}} \bar{g}_{I}
$$

where $v_{i} \equiv \varepsilon_{g i}-[(n-1) /(\gamma n)] \vartheta_{i}$ for all $i,{ }^{6} \tilde{H} \equiv \tilde{\pi}_{u}+\left[-A \varepsilon_{u}+\vartheta_{u}+\lambda A\left(\pi_{u}^{w}-\tilde{\pi}_{u}\right)\right] / d$, and $\bar{g}_{I} \equiv \sum_{i \neq I} \varphi_{i} g_{i}$ is the weighted average of deficits in countries other than $I$. The deficit is thus raised in the event of shocks $v_{I}$ at home, union-wide developments in $\tilde{H}$ (including wage inflation pressures), and deficits $\bar{g}_{I}$ incurred elsewhere in the union.

Monetary-fiscal interaction can also be gauged by replacing Equation (16) with Equation (17) to get

$$
g_{I}=\varepsilon_{g I}-\frac{n^{-1}}{\gamma n+n^{-1}}\left[\left(\varepsilon_{g I}-\varepsilon_{g u}\right)+\left(\vartheta_{I}-\vartheta_{u}\right)\right]+\frac{n^{-1}}{\gamma n} A\left[-\varepsilon_{u}+\lambda\left(\pi_{u}^{w}-\tilde{\pi}_{u}\right)\right]
$$

Optimal fiscal policy is seen to increase the deficit $g_{I}$ in response to a positive fiscal shock $\varepsilon_{g I}$, which is partially offset by an interest rate hike if the fiscal shock exceeds the union average as captured by the expression $\varepsilon_{g I}-\varepsilon_{g u}$. In addition, the fiscal stance is eased if demand factors

\footnotetext{
${ }^{6}$ Composite shock $V_{i}$ can be interpreted as fiscal shock $\varepsilon_{g I}$ net of the fraction, given by $(n-1) / n$, of the exogenous factors affecting demand in $\vartheta_{I}$ that is not offset by the single monetary policy. This fraction is, in turn, appropriately rescaled by fiscal policy preference parameter $Y$.
} 
in $\vartheta_{i}$ 's are more contractionary at home than in the rest of the union $\left(\vartheta_{I}<\vartheta_{u}\right)$. The second term carries in front the factor $(n-1) /(\gamma n+n-1)$, which lies between 0 and 1 . The less-than-full impact implied by this factor for idiosyncratic demand-side developments (that is, cases where $\varepsilon_{g I} \neq \varepsilon_{g u}$ and/or $\vartheta_{I} \neq \vartheta_{u}$ ) reflects the following result: The higher the interest of the government in the fiscal outcome target; that is, the higher the $\gamma$, and thus the lower the factor $(n-1) /(\gamma n+n-$ $1)$, the lower the fiscal authority's interest in offsetting fluctuations in output as arising from country-specific demand developments. Finally, fiscal policy is relaxed in the face of adverse supply factors affecting the last term of Equation (18). ${ }^{7}$

The presence of terms other than $\varepsilon_{g I}$ in Equation (18) reflects the notion that, in some plausible scenarios, the currency union's central bank does not discipline fiscal actions, contrary to what was the case in the monetary autonomy case. Suppose that a given fiscal authority has a reason (as given by an adverse union-wide supply shock) to increase its deficit in order to mitigate the worsening economic conditions at home. Given that each fiscal authority only has an effect proportional to $1 / n$ of the union's economy, it looks as if it could pursue unilateral actions (holding all other choices fixed) and still attain the best possible outcome. Nonetheless, all other national fiscal authorities are embarking in similar actions, and the end result simply increases in nominal interest rate beyond what would have otherwise taken place. This is indicative of a typical coordination failure as given by the problem of free riding in a currency union. All fiscal authorities would be better off in a cooperative equilibrium, in which they agree to a common fiscal policy of balanced budgets, thereby achieving the same outcome as under monetary autonomy (in the absence of fiscal shocks). One way out of the coordination failure involved is the type of constraints imposed in Europe's Stability and Growth Pact, with the ceiling on national deficits being $g_{i}$ 's.

Using Equation (18), the interest rate reaction function Equation (16) can be written as:

$$
R=\tilde{\pi}_{u}+\frac{\varepsilon_{g u}+\vartheta_{u}}{d}+\frac{A}{d}\left(\frac{\gamma n+n^{-1}}{\gamma n}\right)\left[-\varepsilon_{u}+\lambda\left(\pi_{u}^{w}-\tilde{\pi}_{u}\right)\right]
$$

The interest rate reflects the union-wide inflation target and is raised in response to aggregate demand pressures (see $\varepsilon_{g u}+\vartheta_{u}$ term) and adverse supply developments grouped in the last composite term in Equation (19).

In a globalised world, setting interest rates faces considerable challenges. By becoming a larger economy, member states forming a currency union may be in a position to improve the overall effectiveness of their monetary policy actions. This paper also shows that, for some cross-country distributions of shocks and parameter configurations, monetary autonomy (including, for instance, inflation targeting strategies) may be the most desirable option.

\footnotetext{
${ }^{7}$ Within this last term, the supply shock and the wage inflation term have different signs. As we show below, the former term prevails, as wage inflation is itself driven by the supply shock but reacts to it less than one to one due to wage-setting institutions' sensitivity to output developments.
} 
The individual country output can be expressed as

$$
y_{I}=\frac{\gamma n}{\gamma n+n^{-1}}\left(\varepsilon_{g I}+\vartheta_{I}-d R\right)
$$

A given trade union $J$ in country $I$ minimises Equation (6) subject to Equation (20). This requires use of the information on the interest rate contained in Equation (19) as well as on the link between wage growth decided by the trade union $\pi^{w}{ }_{i j}$ and union-wide wage growth $\pi^{w}$ :

$$
\pi_{u}^{w}-\tilde{\pi}_{u}=\frac{1}{n}\left[\frac{\pi_{I J}^{w}-\tilde{\pi}_{I}}{m}+\frac{m-1}{m}\left(\bar{\pi}_{I J}^{w}-\tilde{\pi}_{I}\right)\right]+\frac{n-1}{n}\left(\bar{\pi}_{I}^{w}-\overline{\tilde{\pi}}_{I}\right)
$$

where $\bar{\pi}_{I}^{w}$ and $\overline{\tilde{\pi}}_{I}$ are the weighted averages of wage growth and targeted inflation in countries other than $I$, respectively.

Aggregating over trade unions decisions, in a way similar to that used for fiscal policies in the previous section, allows us to obtain wage growth for country $I$ and at the currency union level, respectively, as

$$
\begin{gathered}
\pi_{I}^{w}=\tilde{\pi}_{I}+\frac{\lambda A^{2}}{(\lambda A)^{2}+m m \kappa} \varepsilon_{u}+\frac{\gamma n}{\gamma n+n^{-1}}\left[\left(\vartheta_{I}-\vartheta_{u}\right)+\left(\varepsilon_{g I}-\varepsilon_{g u}\right)\right] \\
\pi_{u}^{w}=\tilde{\pi}_{u}+\frac{\lambda A^{2}}{(\lambda A)^{2}+n m \kappa} \varepsilon_{u}
\end{gathered}
$$

Equation (22) indicates that domestic wage growth rises in response to favourable realisations of either union-wide supply shocks or demand-side domestic pressures in excess of those existing at the currency union level. Equation (23) shows that only the former source of changes in $\pi_{I}^{w}$ (that is, union-wide supply shocks in $\varepsilon_{u}$ ) carries over to the overall wage inflation $\pi^{w}$.

Using Equation (23), the monetary and fiscal policy feedback rules can be rewritten as

$$
\begin{gathered}
R=\tilde{\pi}_{u}+\frac{\varepsilon_{g u}+\vartheta_{u}}{d}-\frac{A}{d}\left(\frac{\gamma n+n-1}{\gamma n}\right) \frac{n m \kappa}{(\lambda A)^{2}+n m \kappa} \varepsilon_{u} \\
g_{I}=\varepsilon_{g I}-\frac{n-1}{\gamma n+n-1}\left[\left(\varepsilon_{g I}-\varepsilon_{g u}\right)+\left(\vartheta_{I}-\vartheta_{u}\right)\right]-\frac{n-1}{\gamma n} \frac{n m \kappa}{(\lambda A)^{2}+n m \kappa} a \varepsilon_{u}
\end{gathered}
$$

In Equation (14), the interest rate rises above the inflation target to counter union-wide forces given by favourable demand shocks (second term) and adverse supply shocks (third term). The response of $R$ to the latter disturbances reflects two factors: i) the free rider problem, which shows in ratio $(\gamma n+n-1) / \gamma n$ and ii) a stabilising element that is introduced by the wage bargaining process and appears in the fraction $n m \kappa /\left[(\lambda A)^{2}+n m \kappa\right]$, which is bound above at Equation (1). This dampening stems from governments and trade unions both caring about output stability. 
Our result that the free rider problem is mitigated due to wage moderation in the face of supply shocks deserves further discussion. Implicitly, this dampening effect should be understood against the alternative of unresponsive real wages (that is, $\pi_{u}{ }_{u} \tilde{\pi}_{u}$ at the currency union level). This would mean that the monetary union faces an extremely high degree of real wage rigidity. In comparison, wage bargaining as characterised by loss function, Equation (5) is found to enhance real wage flexibility due to trade unions' sensitivity to output effects induced by aggregate supply disturbances.

Finally, we use Equations (1) with $\pi_{I}^{e}=\tilde{\pi}_{I},(18),(19)$, and (20) to find the output gap and inflation rate for individual member state $I$, denoted by $y_{I}^{u}$ and $\pi_{I}^{u}$, respectively:

$$
\begin{gathered}
y_{I}^{u}=\left[\frac{n m \kappa}{(\lambda A)^{2}+n m \kappa}\right] A \varepsilon_{u}+\frac{\gamma n}{\gamma n+n-1}\left[\left(\varepsilon_{g I}-\varepsilon_{g u}\right)+\left(\vartheta_{I}-\vartheta_{u}\right)\right] \\
\pi_{I}^{u}=\tilde{\pi}_{I}-\frac{(1-A)}{\alpha}\left[\frac{n m \kappa}{(\lambda A)^{2}+n m \kappa}\right] \varepsilon_{I}-\left[\frac{\lambda^{2} A+n m \kappa}{(\lambda A)^{2}+n m \kappa}\right] \frac{A}{\alpha}\left(\varepsilon_{I}-\varepsilon_{u}\right) \\
+\frac{1}{\alpha}\left(\frac{\gamma n}{\gamma n+n-1)}\right)\left[\left(\varepsilon_{g I}-\varepsilon_{g u}\right)+\left(\vartheta_{I}-\vartheta_{u}\right)\right]
\end{gathered}
$$

In Equations (26) and (27), macroeconomic developments in country $I$ as given by $y_{I}^{u}$ and $\pi_{I}^{u}$ are affected not only by idiosyncratic supply shocks as was the case under monetary autonomy but also by supply shocks to other countries and unexpected factors captured by $\vartheta_{i}$, hitting the demand side of every participating economy. ${ }^{8}$ With respect to the latter factors, when they display cross-country variation, they give rise to a welfare loss incurred by participating countries - a loss that fails to occur under monetary autonomy. The reason is that the single monetary policy cannot handle a country's specificity like a national central bank. The cases in which exogenous demand factors are country-specific make the difference, with monetary autonomy thus outperforming the currency union for demand-driven economies. Turning to the welfare implications of supply shocks, they are found to be more complex given that they are able to affect macroeconomic developments, and thus welfare, both under monetary autonomy and currency union membership. In this regard, we now proceed to a more detailed quantitative investigation of supply shocks.

It is worth probing how monetary-fiscal interaction under a currency union changes with respect to the case of monetary autonomy. Fiscal deficits create aggregate demand pressures that can be offset by tighter autonomous monetary policies. In a monetary union this is strictly true only when fiscal deficits are fully synchronised. Otherwise, the single monetary authority reacts in proportion to the contribution that each country's fiscal deficit makes to aggregate

\footnotetext{
${ }^{8}$ Uhlig (2003) likens cross-country (output and inflation) adjustments of this sort to the Balassa-Samuelson-type real-side effects that influence the new EU member states.
} 
demand determination. As a result, individual countries' deficits are only partially offset, with the induced interest rate movements transmitting the fiscal shocks across countries.

\section{Welfare Implications}

We draw welfare implications on the basis of sensitivity analysis. We focus on supply disturbances since these are the only ones to influence the loss functions of both the single monetary authority and the national central bank. In all other cases, relinquishing monetary sovereignty purely implies higher stabilisation costs for participating countries. Most of our baseline parameter values follow calibrations previously used for small open economies. The supply slope; that is, $\alpha^{\prime} \equiv 1 / \alpha$ is set to 0.4 while $\beta=0.6, \delta=0.2$, and $\theta=0.5$ (Ball 1999). This implies $d=1$. Our benchmark value for $\varphi$ is 0.1 , implying a value of $n=10$. Lacking calibrations for $\chi$ for small open economies, we use a benchmark value of 2.5 , which is very close to Broadbent and Barro's (1997) estimate using US data. Concerning the calibration of wage-related parameters, we lacked guidance from previous studies and thus set $\lambda=0.2, \varphi_{m} \equiv 1$ / $m=0.1$ and $\kappa=1 .{ }^{9}$ Fiscal authorities' weight on instrument stabilisation $\gamma$ need not be calibrated since it does not influence the supply shocks' impact on macroeconomic developments (see Equations (26) and (27) as well as their monetary autonomy counterparts). Our sensitivity study will allow parameters to vary over the ranges $\alpha \in[0.2,0.6], \varphi \in[0.5,5], \chi \in[0.05,0.5], \varphi_{m} \in[0.05$, $0.5], \kappa \in[0.5,5], \lambda \in[0.05,0.5]$.

In order to study the stabilisation performance of a currency union we look at the ratio $C_{u I}$ $L_{I u} / L_{l}$, which relates the value of the loss function of the monetary authority under a currency union to that obtained under autonomous monetary policy. Figures 1 through 6 show how relative welfare loss $C_{u I}$ changes in relation to the six aforementioned parameters under aggregate supply shocks, also depending on the cross-country distribution of shocks. Welfare comparisons are affected by the interaction of monetary policy with fiscal authorities and trade unions. It is thus important to look at fractions $n m \kappa /\left[(\lambda A)^{2}+n m \kappa\right]$ (relevant under currency union participation) and $m \kappa /\left[(\lambda A)^{2}+m \kappa\right]$ (relevant under monetary autonomy), which feature in Equations (26) and (27) for output and inflation, respectively. Both fractions lie between 0 and 1, which captures a partial stabilisation of supply shocks' macroeconomic consequences in each regime, aligning well with both governments and wage-setting institutions caring about output stability. Under supply shocks of the common type, the welfare ratio $C_{u I}$ is affected by the values of the two aforementioned fractions in relation with each other; that is, for given parameter values the part of common shocks that fails to be offset by interest rate changes is larger under a currency union. In this regard, of the two fractions in question it is

\footnotetext{
${ }^{9}$ Parameter $\varphi_{m}$ simply measures the size of any given trade union in each and every country.
} 
$n m \kappa /\left[(\lambda A)^{2}+n m \kappa\right]$ (the one associated with monetary union) that is larger due to the latter arrangement's multi-country nature $(n>1)$.

There are differences between the results for the case of common shocks, on the one hand, and country-specific shocks (that is, idiosyncratic and asymmetric shocks), on the other. Under common shocks, the stabilisation costs raised by a currency union do not appear to be much different from those arising under autonomous monetary policies. This is hardly surprising, in light of the implied similarities between the problems facing the monetary authority in each regime. The aforementioned fractions do not appear to have a very large impact, tending to imply that relative welfare $C_{u I}$ is rather insensitive to parameter values. ${ }^{10}$ No considerable implications are in particular detected in Figures 1,2, 3, and 5, corresponding to parameters $\chi$, $\alpha^{\prime}, \chi, \varphi$, and $\kappa$, respectively. Only the two remaining parameters exhibit perceptible, if rather small, welfare implications due to also having a larger effect on the previously mentioned fractions (and more precisely, on either of them in relation to the other). These two parameters are wage-related; namely, $\varphi_{m}$ and $\lambda$ (see Panel A of Figures 4 and 6, respectively). An increase in $\lambda$ is found to hamper a currency union's stabilisation performance as it reduces the fraction of inflation variability that is not offset by monetary policy by more than when the latter is run autonomously. Helping explain this result, an enhanced sensitivity of economic activity to wage developments entails a worsening of the output-inflation tradeoff facing the single monetary authority, also relative to monetary autonomy. Concerning $\varphi_{m}$, the increase in the size of trade unions and thus a reduction in their number per country allows interest rate decisions to dampen a larger fraction of supply-driven inflation variability in a currency union even compared with monetary autonomy. The task of the common central bank is facilitated by the result that fewer trade unions internalise a larger fraction of the impact of their wage setting on output stability. However, the corresponding stabilising contribution is stronger under monetary autonomy, thereby implying that a higher $\varphi_{m}$ has a relatively detrimental impact on the single monetary policy. To put it differently, wage bargaining decentralisation overall favours monetary union relative to the case where interest rates are set autonomously.

Turning to the welfare analysis under country-specific shocks (see Panels B and C of Figures 1 through 6), a currency union's stabilisation performance is affected by the way this regime copes with the supply shock gap $\varepsilon_{I}-\varepsilon_{u}$ featuring in the third term of domestic inflation, Equation (27). The latter term captures spillover effects on a given country's inflation from other countries' reactions to the supply shock differential. Such spillover involves the reaction of the interest rate to a country-specific disturbance, taking into consideration the propagation response through the rest of the union. It is worth noting that, by activating the third term of Equation (27), the presence of country-specific shocks involves ratio $\left[\lambda^{2} A+n m \kappa\right] /\left[(\lambda A)^{2}+n m \kappa\right]$ appearing in front of such term.

\footnotetext{
${ }^{10}$ This is related to the fact that, for the range of parameter values considered here, both fractions are rather large, thereby tending to be little affected in the context of our sensitivity analysis.
} 
Figures 1. Relative welfare under monetary-fiscal-wage interaction: Sensitivity to $\alpha^{\prime}$
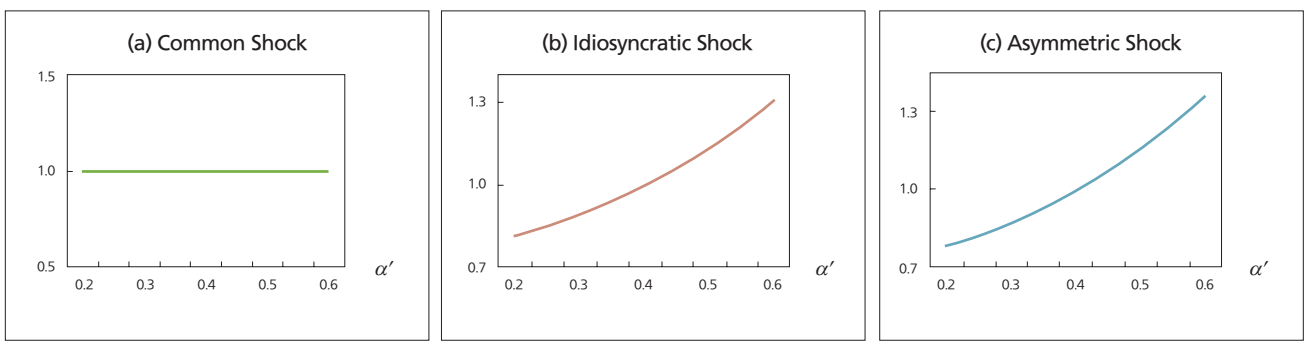

Figures 2. Relative welfare under monetary-fiscal-wage interaction: Sensitivity to $X$
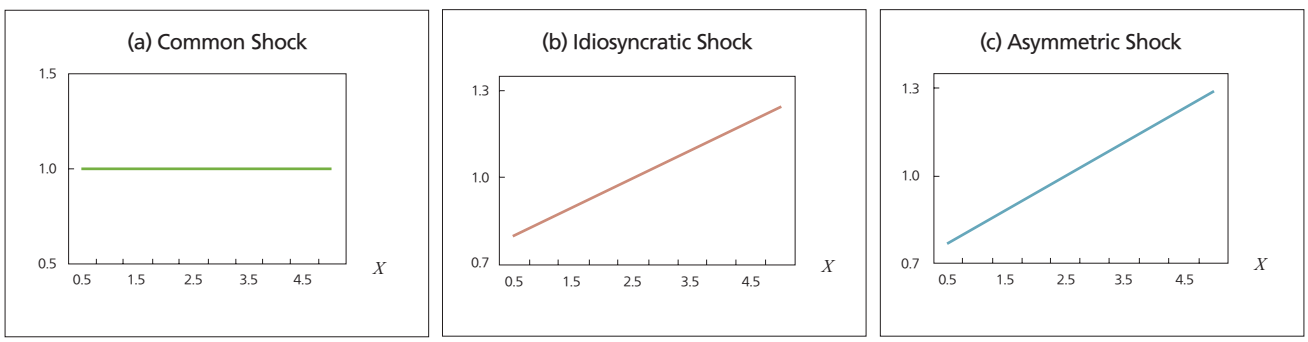

Figures 3. Relative welfare under monetary-fiscal-wage interaction: Sensitivity to $\phi$
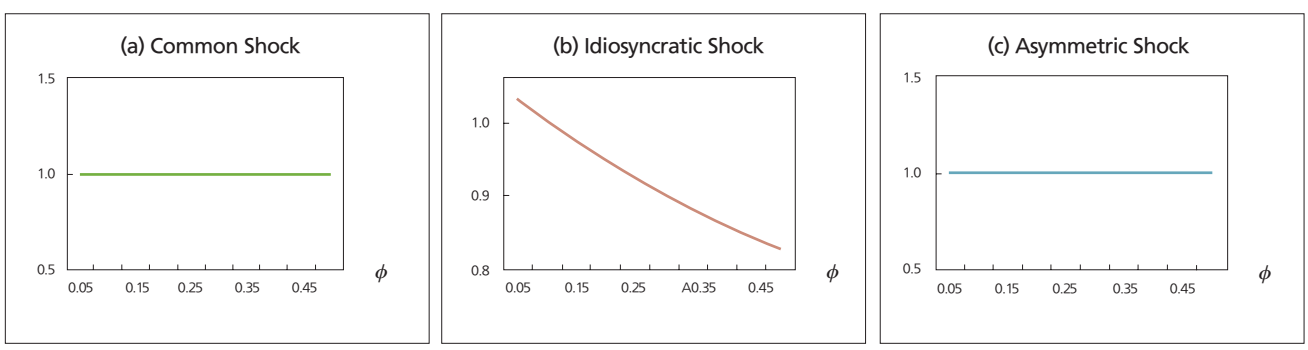

Figures 4. Relative welfare under monetary-fiscal-wage interaction: Sensitivity to $\phi_{m}$
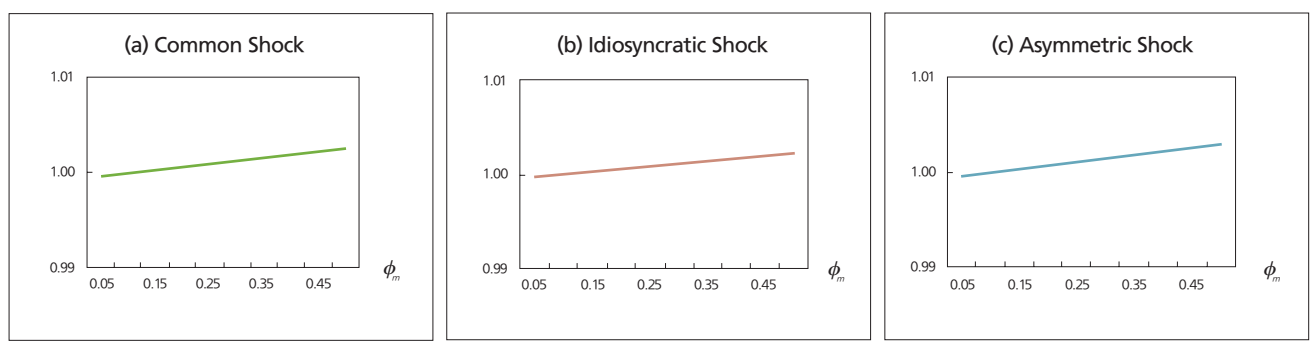
Figures 5. Relative welfare under monetary-fiscal-wage interaction: Sensitivity to $\kappa$
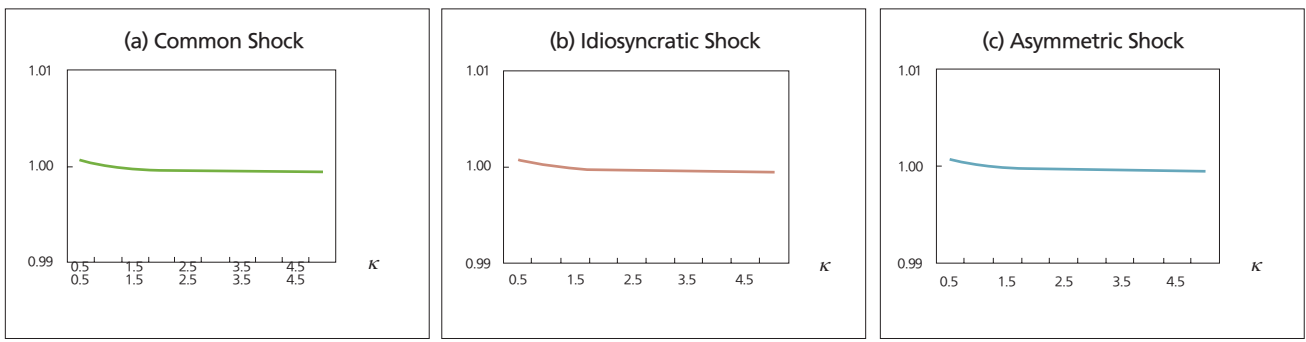

Figures 5. Relative welfare under monetary-fiscal-wage interaction: Sensitivity to $\lambda$
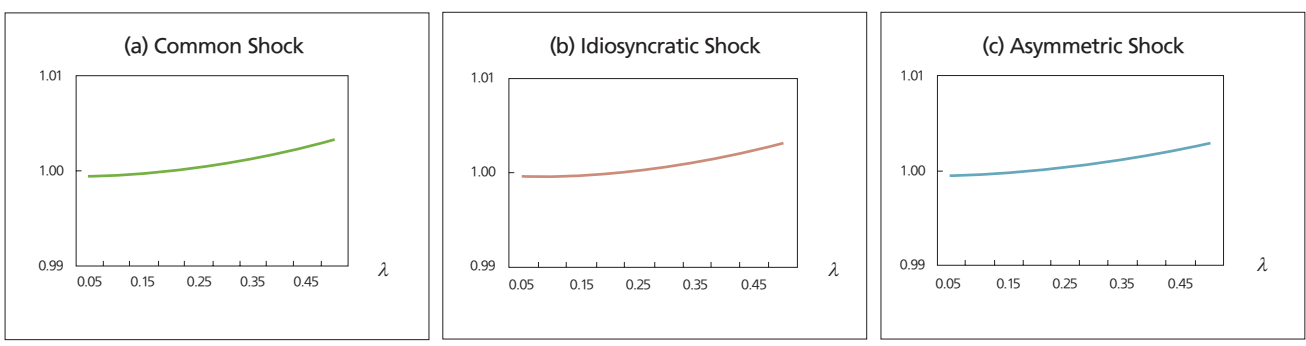

Under country-specific disturbances, sensitivity results are as follows. An increase in the supply slope $\alpha^{\prime}$ has an adverse influence on a monetary union's relative stabilisation properties (Figure 1). The mechanism in play here is somewhat complex, involving two different forces. First, this parameter change makes the relative stabilisation costs under a currency union larger through the worsening of the output-inflation tradeoff. Second, a steeper supply curve raises ratio $\left[\lambda^{2} A+n m \kappa\right] /\left[(\lambda A)^{2}+n m \kappa\right]$ in the third term of Equation (27), thereby aggravating the deterioration in a currency union's stabilisation performance via higher inflation volatility. The intuition for the latter channel is that the interest rate rise induced by adverse supply shock at home entails reactions from governments and trade unions in the rest of the union aimed at mitigating the impact on foreign output stability. As a result, the increase in the interest rate is moderated, thereby leading to higher inflation variability in country $I$. The interest rate hike would have been larger in the absence of spillovers, and in particular under monetary autonomy. Given the positive link between supply slopes and the degree of openness, an across-the-board increase in the latter among participating states can overall be seen as having adverse consequences on monetary union stabilisation performance.

A more conservative central bank (as given by a higher $\chi$ ) also hampers a currency union's stabilisation performance (see Figure 2). The effect of $\chi$ on welfare ratio $C_{u I}$ can be decomposed into two components. First, an increased preference for price stability deteriorates the single monetary policy's performance by penalising domestic inflation volatility-harder to control in a currency union - more harshly. Second, the latter reaction is reinforced by the same 
type of spillover effect as described for a steeper supply curve. This involves a propagation mechanism operating via the foreign reactions of fiscal authorities and wage-setting institutions. The analogy between this parameter change and a higher $\chi$ is intuitive since both entail a rise in the share of a supply disturbance's impact on inflation relative to output that is intended to be offset by monetary policy.

In Figure 3, we consider a rise in $\varphi$. This parameter change may affect welfare only in the currency union. This is not the case when shocks are asymmetric, in light of this type of shock's definition. For idiosyncratic supply disturbances, the increase in country size tends to induce a favourable effect from currency union participation. In terms of the inflationary effect of such shock, the reason behind this is that a higher $\varphi$ implies a reduction in the intensity of both the third and fourth terms of Equation (27) as the single monetary policy puts a larger weight on each country's macroeconomic variables when determining its interest rate decision. Therefore, this decision gets closer to what would have been done under monetary autonomy. Similarly, output fluctuations in Equation (26) approach those under monetary autonomy as $\varphi$ becomes larger.

The welfare implications of the remaining parameters are the following. As in the case of common shocks, changes in the trade unions' weight on real wage growth stability $\kappa$ fail to have any noticeable impact on relative welfare $C_{u I}$ (Figure 5). In turn, higher values for either $\varphi_{m}$ or $\lambda$ induce a currency union to exhibit worse stabilisation properties than monetary autonomy (Figures 4 and 6, respectively). These results involve the relative intensity with which these parameter changes shrink the fraction of inflation variability that fails to be offset by the single monetary policy as described in more detail for the case of common disturbances. Moreover, the welfare effects of $\varphi_{m}$ or $\lambda$ can be traced to the monetary-fiscal-wage interactions influencing the third term of Equation 27. To see the latter, note that ratio $\left[\lambda^{2} A+n m \kappa\right] /\left[(\lambda A)^{2}\right.$ $+n m \kappa]$ is decreasing in $m$ and thus increasing in $\varphi_{m}$, as well as increasing in $\lambda$. Intuitively, a higher $\varphi_{m}$ as given by a smaller number of a given country's trade unions, leads the latter to internalise less of the effect that their wage demands exert on the supply side of the economy. This deteriorates a currency union's stabilisation performance, in line with what was discussed for the case of a larger $\varphi$. Finally, an increase in $\lambda$ favours monetary autonomy over its alternative by making the output-inflation tradeoff worse, resembling the mechanism discussed for a steeper supply schedule.

\section{Conclusion}

We analyse monetary stabilisation in a currency union of small open economies where monetary policy interacts with national fiscal policies and wage-setting institutions. The interplay between monetary policies and uncoordinated fiscal actions gives rise to a free 
rider problem. This problem arises in a context in which the single monetary authority fails to discipline national fiscal authorities in the event of adverse union-wide supply shocks. Each of the governments aims at mitigating the economic consequences of the domestic disturbance. All other fiscal authorities embark in similar actions, the end result simply being a more pronounced rise in the nominal interest rate as the common central bank reacts to larger government deficits. The presence of such coordination failure raises the need for institutions to make fiscal authorities focus on budget considerations as opposed to reacting to cyclical fluctuations. In the EMU context, the Stability and Growth Pact can be interpreted to fulfil this need by putting a cap on national deficits.

This paper evaluates how wage-setting considerations affect the free rider problem and whether they facilitate or hamper monetary stabilisation performance. Trade unions are modelled as caring about real wage stability and output stability. Wage bargaining of this type is found to damp down to some extent the intensity with which uncoordinated national fiscal policies lead to higher interest rate volatility. The extent to which the free rider problem is mitigated decreases with the number of trade unions as higher decentralisation implies that each union internalises less of the adverse effect of wage demands on the supply side of the economy. This effect induced by a larger number of trade unions is, however, stronger under monetary autonomy, with decentralised wage bargaining overall improving a currency union's stabilisation performance. Despite the moderation in free riding intensity, the phenomenon subsists in the wage bargaining context here considered. Therefore, the case for fiscal constraints on government deficits remains relevant for monetary union after taking wage setting into account.

Our welfare analysis of monetary union points to the need to distinguish between exogenous factors impacting the demand and supply sides of participating states. In countries that are driven by shocks hitting the demand side of their economies, currency union participation is adversely affected. This outcome occurs unless exogenous demand factors are uniform across member states, in which case monetary autonomy and a currency union yield the same outcome. Turning to the case of supply shocks, modifications to both supply schedule slopes and preference for price stability have welfare implications that depend on the distribution of shocks within the union. For common shocks, neither of these two parameter changes has any effect on the stabilisation performance of a currency union. For country-specific disturbances, both a steeper supply curve and a higher preference for price stability make the single monetary policy less effective compared to that conducted autonomously. ${ }^{11}$ Moreover, country-specific disturbances overall favour the monetary union membership of countries with larger size.

The results for the wage-related parameters are found to hold regardless of whether disturbances are common or country-specific. Monetary union stabilisation performance

\footnotetext{
"We leave for further research the case when the supply slopes differ across countries. Abstracting from fiscal and wage complications, Sánchez $(2007 \mathrm{a}, 2008 \mathrm{c})$ shows that a given member country can benefit from becoming more open relative to other participating states.
} 
is hampered by a larger sensitivity of output to wages and an increase in the size of trade unions (more centralised wage bargaining), although these welfare implications appear to be quantitatively small. Wage bargaining produces a partially stabilising effect on macroeconomic developments in comparison with a pure monetary-fiscal game. Higher wage bargaining decentralisation turns out to dampen this favourable result, given that each union internalises less of the damaging effect of wage inflation on the tradeoff between output and inflation. This effect of wage bargaining decentralisation is, however, stronger under monetary autonomy, thereby being consistent with the summary result that a larger (smaller) trade union size overall hampers (improves) a currency union's stabilisation performance. The focus here is on conjunctural stabilisation matters, which differs from the longer-run considerations favouring wage bargaining decentralisation for its flexibility-enhancing implications (OECD 2007). Finally, changes in the trade unions' weight on real wage growth stability do not exert detectable relative welfare influences.

Received 30 November 2012, Revised 27 March 2013, Accepted 19 April 2013

\section{References}

Alesina, A., and Spolaore, E.(2003). The Size of Nations. Cambridge, MA: MIT Press.

Alesina, A., Spolaore, E., and Wacziarg, R.(2005). "Trade, Growth and the Size of Countries", in Aghion, P., and Durlauf, S. (eds.) Handbook of Economic Growth. Amsterdam: North Holland.

Ball, L.(1999). "Policy Rules for Open Economies", in Taylor, J. (ed.), Monetary Policy Rules. Chicago: University of Chicago Press.

Ball, L.(2002). "Policy Rules and External Shocks", in Loayza, N., Schmidt-Hebbel, K.(eds.), Monetary Policy: Rules and Transmission Mechanisms. Santiago: Central Bank of Chile.

Bratsiotis, G., and Martin, C.(1999). "Stabilisation,. Policy Targets and Unemployment in Imperfectly Competitive Economies”, Scandinavian Journal of Economics 101, 241-257.

Broadbent, B., and Barro, R.(1997). “Central Bank Preferences and Macroeconomic Equilibrium”, Journal of Monetary Economics 39, 17-43.

Calmfors, L., and Johansson, A.(2006). "Nominal Wage Flexibility, Wage Indexation and Monetary Union", Economic Journal 116, 283-308.

Chari, V., and Kehoe, P.(2008). “Time Inconsistency and Free-Riding in a Monetary Union”, Journal of Money, Credit, and Banking 40, 1329-1356.

Dixit, A., and Lambertini, L.(2001). "Monetary-Fiscal Policy Interactions and Commitment versus Discretion in a Monetary Union”, European Economic Review 45, 977-987.

Dixit, A., and Lambertini, L.(2003). "Symbiosis of Monetary and Fiscal Policies in a Monetary Union", Journal of International Economics 60, 235-247.

Erceg, C., Gust, C. and Lopez-Salido, D.(2009). "The Transmission of Domestic Shocks in Open Economies", 
in Galí, J., and Gertler, M. (eds.), International Dimensions of Monetary Policy. Cambridge MA: The MIT Press.

Galí, J., and Monacelli, T.(2008). "Optimal Monetary and Fiscal Policy in a Currency Union”, Journal of International Economics 76, 116-132.

Herrendorf, B., and Lockwood, B.(1997). "Rogoff's "Conservative" Central Banker Restored", Journal of Money, Credit, and Banking 29, 476-495.

Holden, S.(2005). "Monetary Regime and the Co-ordination of Wage Setting", European Economic Review 49, 833-843.

Hutchison, M., and Walsh, C.(1998). "The Output-Inflation Tradeoff and Central Bank Reform: Evidence from New Zealand”, Economic Journal 108, 703-725.

OECD(2007). Economic Surveys: Euro Area. Paris: OECD.

Onorante, L.(2006). "Fiscal Convergence Before Entering the EMU”, ECB Working Paper No 664.

Oswald, A.(1985). “ The Economic Theory of Trade Unions: An Introductory Survey”, Scandinavian Journal of Economics 87, 160-193.

Romer, D.(1993). “Openness and Inflation: Theory and Evidence”, Quarterly Journal of Economics 108, 869903.

Sánchez, M.(2006). "Is Time Ripe for a Currency Union in Emerging East Asia? The Role of Monetary Stabilisation”, Journal of Economic Integration 21, 736-763.

Sánchez, M.(2007a). "Monetary Stabilisation in a Currency Union: The Role of Catching up Member States", Journal of Policy Modeling 29, 29-40.

Sánchez, M.(2007b). "How Does Information Affect the Comovement between Interest Rates and Exchange Rates?”, Rivista Internazionale di Scienze Sociali 4/2007, 547-562.

Sánchez, M.(2008a). "The Link between Interest Rates and Exchange Rates: Do Contractionary Depreciations Make a Difference?”, International Economic Journal 22, 43-61.

Sánchez, M.(2008b). "Monetary Stabilisation in a Currency Union of Small Open Economies", ECB Working Paper No. 927.

Sánchez, M.(2008c). "Implications of Monetary Union for Catching-up Member States", Open Economies Review 19, 371-390.

Svensson, L.(2000). “Open-Economy Inflation Targeting”, Journal of International Economics 50, 155-183.

Uhlig, H.(2003). “One Money, but Many Fiscal Policies in Europe: What are the Consequences?”, in Buti, M. (ed.), Monetary and Fiscal Policies in EMU: Interactions and Co-ordination. Cambridge: Cambridge University Press. 